\title{
Caracterização das unidades de produção agrícola que usam agrotóxicos em Vacaria (RS)
}

\author{
Characterization of the agricultural production units using pesticides \\ in Vacaria (RS)
}

Nilva Lúcia Rech Stedile ${ }^{1}$ (D) Neice Muller Xavier Faria² (D), Suzete Marchetto Claus $^{3}$ (D), Danusa Santos Brandão ${ }^{4}$ (])

\begin{abstract}
`Área de Conhecimento de Ciências da Vida, Programa de Pós-graduação em Engenharia e Ciências Ambientais, Universidade de Caxias do Sul (UCS), Caxias do Sul (RS), Brasil. E-mail: nlrstedi@ucs.br

2 Departamento de Medicina Social, Universidade Federal de Pelotas (UFPEL), Bento Gonçalves (RS), Brasil. E-mail: neicef@yahoo.com.br 3 Área de Conhecimento de Ciências da Vida, Núcleo de Estudos e Pesquisas em Saúde Coletiva (NEPESC), Universidade de Caxias do Sul (UCS), Caxias do Sul (RS), Brasil. E-mail: smclaus@ucs.br

${ }^{4}$ Setor de Vigilância em Saúde, Secretaria Municipal de Saúde de Caxias do Sul (RS), Caxias do Sul (RS), Brasil. E-mail: danusasb@ gmail.com
\end{abstract}

\begin{abstract}
Como citar: Stedile, N. L. R., Faria, N. M. X., Claus, S. M., \& Brandão, D. S. (2022). Caracterização das unidades de produção agrícola que usam agrotóxicos em Vacaria (RS). Revista de Economia e Sociologia Rural, 60(spe), e234912. https://doi.org/10.1590/1806-9479.2021.234912
\end{abstract}

Resumo: As características das unidades produtivas (UP) e o uso de agrotóxicos são importantes para avaliar riscos à saúde humana e ambiental. Este estudo buscou descrever os aspectos das UP relacionados ao uso dos agrotóxicos e identificar possíveis práticas de risco para os trabalhadores. Estudo descritivo, a partir de entrevistas realizadas em 426 UP. Foi avaliada área (em módulos fiscais), mata nativa, produção vegetal e animal, nível de mecanização, uso e manejo de agrotóxicos e orientações técnicas. A análise incluiu medida de tendência central e de dispersão e análise de proporções. Associações foram examinadas com teste quiquadrado de Pearson e de tendência linear. Não houve diferença na proporção de mata nativa conforme área. As UP maiores apresentavam maior nível de mecanização. O uso de agrotóxicos foi relatado por 96,5\% das UP. As maiores UP usavam práticas mais adequadas no armazenamento, no destino das embalagens e tinham mais orientações de técnicos. Independentemente do tamanho da UP foram verificados problemas de gerenciamento dos riscos, em especial nas embalagens de produtos veterinários. Existem diferenças importantes no manejo de agrotóxicos entre as diversas UP, mas em geral os trabalhadores agrícolas estão em situação de vulnerabilidade socioambiental devido à exposição química intensa.

Palavras-chave: agrotóxicos, uso de praguicidas, agricultura, saúde ocupacional, saúde ambiental.

\begin{abstract}
The characteristics of the Production Units (PU) in rural areas and the use of pesticides are important to assess risks to human and environmental health. This study aimed to describe the factors of PUs related to the use of pesticides and identify possible risk practices for workers. Descriptive study based on interviews carried out in 426 PU. The area (in fiscal modules), native forest, plant and animal production, level of mechanization, use, and handling of pesticides, and technical guidance were evaluated. The analysis included measures of central tendency and dispersion and proportions' analysis. Associations were examined using Pearson's Chi-square and Linear Trend. There was no difference in the proportion of native forest according to the area. Larger PUs had a higher level of mechanization. The use of pesticides was reported by $96.5 \%$ of the PU. The largest PU used more adequate practices in storage, in the destination of the packages, and had more technical guidance. Regardless of the size of the $\mathrm{PU}$, there were problems with risk management, especially in the packaging of veterinary products. There are important differences in the management of pesticides between the different PUs, but in general agricultural workers are under socio-environmental vulnerability due to intense chemical exposure.
\end{abstract}

Keywords: agrochemicals, pesticides use, agriculture, occupational health, environmental health.

\section{INTRODUÇÃO}

A denominada "Revolução Verde" nos anos 50 provocou modernização tecnológica e mudanças nas práticas agrícolas, afetando o ambiente, os processos de trabalho e a saúde humana. Em 2017 o 
contingente de trabalhador-agricultor era de 18,2 milhões de pessoas, que representavam 20,1\% da força de trabalho do Brasil (Castro et al., 2020) em ambiente rural, cujas condições geram cargas de trabalho que influenciam diretamente a saúde. Rocha et al. (2015), ao estudarem as cargas de trabalho e os riscos a que estão submetidos agricultores, destacam os de natureza biológica, química e psíquica, ruído e vibrações, a prevalência de acidentes de trabalho e de doenças de pele.

Dentre os riscos socioambientais a que estão submetidos os agricultores, convém destacar os de natureza química pela constância de exposição aos agrotóxicos. Entre 2001 e 2008, a comercialização de agrotóxicos no Brasil saltou de dois para sete bilhões de dólares (Bombardi, 2017), dando ao país o título de campeão mundial no uso desses produtos (Londres, 2011), título que mantém até a atualidade. O consumo de agrotóxicos no Brasil subiu 135\% entre 2010 e 2014 (Bombardi, 2017).

O dossiê produzido pela Associação Brasileira de Saúde Coletiva - Abrasco (Carneiro et al., 2015), com base em estudos científicos nacionais e internacionais, alertou para uma série de problemas à saúde humana e ambiental decorrentes do uso de agrotóxicos. Destacou que um terço de todos os alimentos consumidos no Brasil tem resíduos de agrotóxicos não autorizados ou acima do permitido e que há escassos registros sobre a concentração desses produtos na água e no solo. Além disso, a subnotificação de intoxicações e a comercialização clandestina aumentam ainda mais a distância entre os registros oficiais e a realidade (Faria et al., 2007).

O modelo de produção agrícola hegemônico desenvolvido no Brasil, marcado pela entrada do capitalismo no campo e pela denominada "Revolução Verde" que lhe dá sustentação, envolve a expansão dos latifúndios agroindustriais de alta complexidade tecnológica e afirmam o uso de agrotóxicos (Carneiro et al., 2015, p. 96). Sua lógica aproveita as desigualdades e assimetrias entre grupos sociais, submetendo grande parte dos agricultores a um processo de "vulnerabilidade populacional" (Carneiro et al., 2015, p. 97). Cabe destacar que isso se refere não apenas a questões de exposição, mas também às dificuldades em reconhecer, tornar público e enfrentar riscos, a ponto de influenciar os processos decisórios e a definição de políticas sociais públicas.

Esse conjunto de fatores afeta principalmente, no Brasil, agricultores que atuam na agricultura familiar e proprietários de unidades de produção agrícola de pequeno porte. Souza et al. (2019), ao buscarem em seus estudos uma medida de intensidade de utilização das principais tecnologias pela agricultura familiar brasileira, concluem, para além da heterogeneidade de distribuição entre as diferentes regiões, que o uso de tecnologias "resulta de uma adaptação dos agricultores a uma série de condicionantes, tais como: dotação relativa de terra, mão de obra e recursos financeiros; o acesso à política de crédito; a infraestrutura regional; o grau de interação com cooperativas, agroindústrias etc.; o nível de capital humano; o grau de organização dos agricultores; o acesso à assistência técnica; o tipo de sistema de produção e as atividades predominantemente desenvolvidas, dentre outras" (p. 613).

Nesse modelo de produção agrícola que usa de forma intensiva os agrotóxicos e outros produtos químicos, algumas características das UP e do processo de trabalho agrícola como, por exemplo, as diferentes formas de aplicação, de armazenamento e de descarte de embalagens podem influenciar os impactos desses produtos químicos na saúde humana, em animais de criação e no meio ambiente. Estudos realizados na Serra Gaúcha avaliaram vários aspectos da produção agrícola e revelaram exposição intensa dos agricultores aos agrotóxicos em Antônio Prado, Ipê (Faria et al., 2000) e Bento Gonçalves (Faria et al., 2009).

Dentre os municípios da Serra produtores de frutas destaca-se Vacaria, pela produção de maçã, sendo o segundo município produtor da fruta e responsável por $25 \%$ da colheita nacional, segundo o Censo Agropecuário 2017 (Instituto Brasileiro de Geografia e Estatística, 2021), além de outras frutas, grãos e pecuária. Em 2010, Vacaria apresenta uma população de 61.342 pessoas, das quais 4.003 eram moradores na zona rural (Instituto Brasileiro de Geografia e Estatística, 2021; DATASUS, 2021). 
Poucos estudos examinaram a relação entre o uso de agrotóxicos sob o ponto de vista das características das unidades produtivas (UP) que os utilizam. Assim, o objetivo deste estudo é descrever as características dessas UP e as práticas utilizadas na gestão dos agrotóxicos, que possam contribuir para a identificação de possíveis riscos à saúde e ao meio ambiente.

\section{CONTEXTUALIZAÇÃO DA TEMÁTICA}

As consequências do uso de agrotóxicos na agricultura têm sido objeto de estudo e interesse em todo o mundo. Essas consequências podem afetar os seres vivos em geral (vegetais e animais), o meio ambiente (água, solo e ar), causando impactos econômicos, ambientais e sobre a saúde das populações.

A definição de agrotóxicos mais amplamente utilizada no país é aquela descrita na Lei Federal n. 7.802 (Brasil, 1989), a qual expõe que os agrotóxicos são:

[...] os produtos e os agentes de processos físicos, químicos ou biológicos, destinados ao uso nos setores de produção, no armazenamento e beneficiamento de produtos agrícolas, nas pastagens, na proteção de florestas, nativas ou implantadas, e de outros ecossistemas e também de ambientes urbanos, hídricos e industriais, cuja finalidade seja alterar a composição da flora ou da fauna, a fim de preservá-las da ação danosa de seres vivos considerados nocivos; substâncias e produtos, empregados como desfolhantes, dessecantes, estimuladores e inibidores de crescimento.

Esse conceito traz uma retórica que liga muito mais esses produtos a uma ação benéfica na natureza, relativizando os riscos que esses insumos representam a quem os manipula diretamente (agricultores), aos consumidores, aos seres vivos e ao meio ambiente. No entanto, estudos têm cada vez mais elucidado os efeitos prejudiciais dos agrotóxicos e a complexidade das variáveis envolvidas nessa relação (Carneiro et al., 2015; Kim et al., 2017; Londres, 2011; Faria et al., 2014; Araújo \& Oliveira, 2017).

A presença dos agrotóxicos nos compartimentos ambientais como consequência do seu uso frequente ou inadequado, especialmente por lixiviação ou carreamento superficial (Jardim et al., 2009), impregna o ambiente e atinge os seres vivos. Dentre os compartimentos mais estudados está a água, cuja presença de agrotóxicos em concentrações acima do recomendado é conhecida, tanto na água superficial (Spadotto et al., 2004) como na subterrânea (Jardim et al., 2009). Estudos mostram que a contaminação de peixes, crustáceos, moluscos não consta das referências de outros animais e representa um forte potencial de contaminação humana, durante consumo como alimento (Soares \& Porto, 2007).

Cabe destacar que diferentes tipos de agrotóxicos contêm poluentes orgânicos persistentes, como clordano, diclorodifeniltricloroetano (DDT), dieldrina, endrina, heptacloro e hexaclorobenzeno, que resistem intensamente à degradação e permanecem no meio ambiente (Yadav et al., 2015 apud Kim et al., 2017). Além disso, os compostos podem ter a capacidade de bioacumulação e biomagnificação em até 70.000 vezes em relação à sua concentração inicial, e a aplicação repetida resulta em perda da biodiversidade, aumento da resistência a pragas e efeitos sobre outras espécies (Kim et al., 2017). De acordo com os mesmos autores, 95\% dos agrotóxicos aplicados impactaram organismos não alvo e se disseminaram no meio ambiente.

Para as pessoas, um dos efeitos mais prejudiciais são as intoxicações, que podem levar inclusive a óbito. O Ministério da Saúde (MS) alerta para o risco de intoxicações agudas, subagudas e crônicas, resultantes da relação complexa entre o organismo e diferentes variáveis, como características químicas e toxicológicas do produto, as relativas ao indivíduo exposto, às vias de penetração no organismo, às condições de exposição ou condições gerais do trabalho. Segundo o Protocolo de Atenção à Saúde dos Trabalhadores Expostos a Agrotóxicos (Brasil, 2006), as intoxicações são classificadas como agudas e crônicas. As agudas são subclassificadas como 
leve, moderada e grave. O Protocolo de Avaliação das Intoxicações Crônicas por Agrotóxicos (Paraná, 2013), caracteriza a intoxicação crônica pelo surgimento tardio de sinais e doenças, após meses ou anos, por exposição, inclusive pequena ou moderada, a produtos tóxicos ou a múltiplos produtos, acarretando danos muitas vezes irreversíveis nos indivíduos expostos.

A exposição das populações aos agrotóxicos pode ocorrer de forma direta ou indireta. A forma direta ocorre pelo manuseio e trabalho com os insumos; a forma indireta pelo local de trabalho próximo às áreas que utilizam agrotóxicos ou pelo consumo de água e alimentos que estejam contaminados (Carneiro et al., 2015). A atividade agrícola foi considerada insalubre, ainda na década de 70 do século passado, pela Norma Regulamentadora n. 15 do Ministério do Trabalho (Brasil, 1978). Portanto, é necessário o uso de EPI, os quais são estabelecidos pelo Decreto n. 4.074/2002 (Brasil, 2002).

De acordo com o Relatório Nacional de Vigilância em Saúde de Populações Expostas a Agrotóxicos (Brasil, 2018), a notificação por intoxicação exógena por agrotóxicos é de ordem obrigatória e deve ser feita diante de suspeita ou confirmação da mesma.

Diversos autores têm examinado os efeitos agudos relacionados aos agrotóxicos, como o surgimento de vômito, diarreia, náuseas, dores abdominais, cefaleia e convulsões, entre outros (Carneiro et al., 2015; Brasil, 2013; Santos et al., 2017). Há também vários estudos cujo foco são os danos crônicos como os cânceres de mama, de próstata, leucemias e linfomas, depressão do sistema nervoso central e fibrose pulmonar, Parkinson, asma, Alzheimer, teratogenicidade e genotoxicidade (Dhananjayan \& Ravichandran, 2018; Kim et al., 2017; Sabarwal et al., 2018; Lopes \& Albuquerque, 2018; Carneiro et al., 2015; Sabarwal et al., 2018).

Apesar do grande número de estudos, um aspecto pouco estudado são as características das unidades de produção agrícola onde se dá o uso de agrotóxicos. Além do modelo de produção agrícola, focado no uso intensivo de agrotóxicos, as diferentes formas de aplicação, de armazenamento e do descarte de embalagens podem influenciar os impactos destes produtos químicos na saúde humana, animais de criação e no meio ambiente.

Estudos na Serra Gaúcha, que é uma importante região em produção agrícola e de criação de animais, verificaram exposição intensa aos agrotóxicos nos municípios de Antônio Prado, Ipê (Faria et al., 2000), com pelo menos $75 \%$ dos trabalhadores rurais relatando contato direto com agrotóxicos. Outro estudo com agricultores de Bento Gonçalves (Faria et al., 2009) verificou proporção de 3,8\% de casos referidos de intoxicações agudas. Mas conforme critérios propostos pela OMS essa proporção seria cerca de $11 \%$ de casos prováveis de intoxicação aguda por agrotóxicos. Bombardi (2017) demonstrou que a região Sul está entre as que mais consomem agrotóxicos do país.

\section{MÉTODO}

Trata-se de um estudo epidemiológico descritivo, tipo inquérito (survey), desenvolvido por meio de entrevistas com os trabalhadores agrícolas, que eram os principais operadores das 426 UP, moradores da zona rural da cidade de Vacaria, Campos de Cima da Serra, Rio Grande do Sul. Vacaria situa-se a uma altitude de 971 m, na região nordeste do Rio Gande do Sul, com clima frio e uma população rural de cerca de 4.000 pessoas no Censo de 2010 (6,5\% do total). A escolha desse tema ocorreu a partir de decisão do Conselho Gestor do Cerest Serra, que levou em conta a deliberação da Conferência Regional de Saúde em priorizar estudos sobre trabalhadores rurais e temas relacionados aos agrotóxicos. Para a escolha do local, levou-se em conta a mobilização de vários atores sociais, como o Sindicato de Trabalhadores Rurais de Vacaria, a Associação Gaúcha de Produtores de Maçã (Agapomi), a Secretaria de Agricultura e Meio Ambiente, a Secretaria Municipal de Saúde e Vigilância em Saúde, o Conselho Municipal de Saúde de Vacaria e a $5^{\text {a }}$ CRS 
- Coordenadoria Regional de Saúde, para que o estudo fosse realizado nesse município. O apoio desses atores contribuiu significativamente para facilitar aspectos logísticos do estudo.

A amostra incluiu os trabalhadores rurais, donos ou responsáveis por 426 UP, situadas na área de abrangência da Estratégia de Saúde da Família (ESF) do município. Na época do início da pesquisa as unidades de ESF tinham uma cobertura estimada em $70 \%$ da população rural, fazendo acompanhamento de saúde de 872 famílias. Foram selecionadas pessoas que tivessem 18 anos e mais e que trabalhassem em atividades agrícolas pelo menos 15 horas/semana. O estudo foi desenvolvido para examinar vários aspectos do trabalho agrícola e na presente análise foram examinados os dados relativos às características das UP.

As entrevistas foram realizadas por entrevistadores treinados, que eram agentes comunitários de saúde da área rural, profissionais da vigilância em saúde e membros do sindicato de trabalhadores rurais. Os agentes comunitários e parte dos demais entrevistadores moravam na área rural do município. $O$ treinamento dos entrevistadores ocorreu em duas etapas: na primeira, com duração de $16 \mathrm{~h}$, foi apresentada a pesquisa e os diferentes aspectos do trabalho agrícola, incluindo uma discussão sobre o uso de agrotóxicos e seus riscos para saúde e meio ambiente. Também foi apresentada uma versão preliminar do roteiro de entrevista. Ao final desta etapa foi realizado um estudo piloto para treinamento prático, testando em campo a logística e os instrumentos de coleta de dados. Após ocorreu a segunda fase do treinamento $(8 \mathrm{~h})$, que revisou os aspectos principais da pesquisa, usando os instrumentos definitivos. De forma conjunta, foi organizada a listagem das famílias elegíveis, conforme critério de seleção e planejado o trabalho de campo. No seu conjunto a pesquisa ocorreu no período entre $2013 \mathrm{e}$ 2015. A coordenação do trabalho de campo ficou a cargo do Cerest e supervisoras da área ambiental do município. Para controle de qualidade foram revisitadas cerca de $10 \%$ das UP, sendo confirmada a entrevista prévia e reexaminadas as principais variáveis.

Para caracterização das UP foram coletados dados sobre área total e tipo de uso, incluindo proporção de mata nativa, principais produções agrícolas (animais e vegetais) e indicadores agroeconômicos (disponibilidade - uso próprio ou alugado - de automóveis, máquinas agrícolas, veículos para transporte de produção). A disponibilidade de máquinas e veículos agrícolas foi considerada como indicador econômico da UP e incluída na avaliação do nível de mecanização. Também foi incluído um bloco de questões caracterizando vários aspectos relacionados ao uso de agrotóxicos. Estes foram definidos no questionário como "produtos químicos usados no controle de pragas na lavoura ou em doenças nos animais de criação, que neste estudo foram chamados de agrotóxicos". Também foram coletados principais tipos químicos, tipos de equipamentos usados na aplicação, locais de armazenamento, destino de embalagens (para agricultura e para pecuária) e acesso a orientações técnicas.

A partir do maquinário agrícola e dos equipamentos usados na aplicação de pesticidas, foi construído um indicador de nível de mecanização da UP, somando as máquinas agrícolas, veículos para transportar produção, trator turbo atomizador, trator com cabine com filtro químico e avião. O resultado dessa pontuação foi dividido em tercis que foram definidos como níveis de mecanização baixo, médio e alto.

O critério utilizado para análise das UP por área foi o de módulos fiscais (MF), estabelecidos pelo Incra (Instituto Nacional de Colonização e Reforma Agrária, 2021), que utiliza o critério previsto na Lei n. 8.629/1993 (Brasil, 1993), levando-se em conta: (a) o tipo de exploração predominante no município (hortifrutigranjeira, cultura permanente, cultura temporária, pecuária ou florestal); (b) a renda obtida no tipo de exploração predominante; (c) outras explorações existentes no município que, embora não predominantes, sejam expressivas em função da renda ou da área utilizada; (d) o conceito de "propriedade familiar". A dimensão de 
um MF varia de acordo com o município e região onde está localizada a propriedade, podendo ter de 5 a 110 hectares (ha), sendo de 25 hectares o MF em Vacaria. Assim, os imóveis rurais são classificados em quatro categorias: minifúndio (imóvel rural com área inferior a um MF); pequena propriedade (entre um e quatro MF); média propriedade (superior a quatro até $15 \mathrm{MF);}$ grande propriedade (superior a 15 MF) (Embrapa, 2021). A ocupação da área foi examinada conforme número de hectares usados para agricultura, pecuária e área de vegetação/mata nativa. Para examinar a distribuição em relação à área por MF, os dados foram agrupados em 3 categorias: não tinha/não relatou área para esse tipo de uso (agricultura, pecuária ou mata nativa), e para aqueles que relataram área específica, duas categorias de área divididas ao meio, conforme percentual usado para cada tipo de uso. Os principais produtos agrícolas, de origem vegetal e animal, foram apresentados conforme proporção de UP em cada grupo de MF.

Os dados foram coletados por meio de entrevistas padronizadas, realizadas com o principal operador de cada UP. Os instrumentos foram codificados e digitados em planilhas por meio da ferramenta FORMSUS e a análise foi processada usando Statistical Package for Social Science(SPSS) para WindowsNersão 22.0. Após a digitação dos dados coletados foi realizada uma revisão para identificar problemas e eventuais inconsistências. Foram identificadas 428 UP, mas devido à ausência dos dados de área, duas foram excluídas dessa análise. Em cada análise foi explicitado qual o total de UP avaliadas e na tabela de gestão dos agrotóxicos foi informado o número de UP que tinham os dados informados, sendo excluídas aquelas com os dados ignorados e/ou inconsistentes, em cada análise. Após revisão e análise exploratória foi construído um panorama descritivo das UP.

As variáveis categóricas foram descritas por meio de frequências absolutas e relativas (análise de proporções) e as variáveis contínuas foram examinadas através de medidas de tendência central (média e mediana) e medidas de dispersão (desvio padrão, valor mínimo e valor máximo). Para avaliar associações significativas foram utilizados os testes qui-quadrado de Pearson e qui-quadrado de tendência linear (sendo apresentado o valor de p mais significativo), de acordo com Bonita et al. (2010). O nível de significância adotado foi de $5 \%$ com poder estatístico de $80 \%$ (valor de $p \leq 0,05$ ).

A pesquisa foi submetida ao Comitê de Ética em Pesquisa /Universidade de Caxias do Sul e aprovada conforme Parecer n. 833.632/14. Todos os entrevistados assinaram um Termo de Consentimento Livre e Esclarecido (TCLE) antes de participar da entrevista.

\section{RESULTADOS E DISCUSSÃO}

O estudo permite uma caracterização representativa do contexto produtivo agrícola da zona rural de Vacaria (RS).

Considerando o total dos elegíveis, houve cerca de 4\% de UP cujas informações não puderam ser obtidas, sendo consideradas como perdas/recusas. Ao final foram avaliados dados de 426 UP onde os trabalhadores agrícolas exerciam suas atividades. Porém, ocorreram dados ignorados em algumas questões, principalmente no bloco de gestão dos agrotóxicos, reduzindo assim o número de UP analisadas para 316, ou seja, uma redução global de $25 \%$ na taxa de respostas.

As UP tinham em média 204,6 hectares-ha (desvio padrão-dp 568,6) sendo a mediana de 50 ha variando de um a 7.000 ha. O valor da mediana equivalia a dois módulos fiscais conforme critério Incra/Embrapa para Vacaria.

Conforme a Tabela 1, foram identificados 131 (30,8\%) minifúndios (menor que 25 ha), 169 (39,7\%) pequenas propriedades (25 a $100 \mathrm{ha}), 72$ (16,8\%) médias propriedades (100,1 a 375 ha) e 54 (12,6\%) grandes propriedades (maior que 375 ha). Excluindo os dados ignorados, a agricultura era desenvolvida em 340 UP, ou seja, cerca de $80 \%$ dos estabelecimentos. A produção animal ocorria em $78,2 \%$ das UP e $74,2 \%$ tinham alguma área de vegetação nativa. 
Tabela 1 - Distribuição das unidades produtivas (UP) avaliadas em Vacaria (RS) segundo a área e tipo de uso da terra $(n=426)$.

\begin{tabular}{|c|c|c|}
\hline Área total & $N=426$ & $100,0 \%$ \\
\hline \multicolumn{3}{|l|}{ Minifúndio: $<1 \mathrm{MF} *(<25 \mathrm{ha})$} \\
\hline Até 9,9 ha & 42 & $9,9 \%$ \\
\hline 10 a 24,9 ha & 89 & $20,9 \%$ \\
\hline Pequenas UP: 1 a 4 MF (25 a 100 ha) & 169 & $39,7 \%$ \\
\hline Médias UP: > 4 a 15 MF (100,1 a 375 ha) & 72 & $16,9 \%$ \\
\hline Grandes UP: > 15 MF (mais de 375 ha) & 54 & $12,7 \%$ \\
\hline \multicolumn{3}{|l|}{ Área para agricultura } \\
\hline Não tem agricultura & 78 & $18,7 \%$ \\
\hline Menos de 4 ha & 103 & $24,6 \%$ \\
\hline 4 a menos de 40 ha & 128 & $30,6 \%$ \\
\hline 40 ha e mais & 109 & $26,1 \%$ \\
\hline \multicolumn{3}{|l|}{ Área para pecuária } \\
\hline Não tem animais & 92 & $21,6 \%$ \\
\hline Menos de 10 ha & 78 & $18,4 \%$ \\
\hline 10 a 39,9 ha & 137 & $32,2 \%$ \\
\hline 40 ha e mais & 118 & $27,8 \%$ \\
\hline \multicolumn{3}{|l|}{ Área de mata nativa } \\
\hline Não tem mata nativa & 103 & $24,6 \%$ \\
\hline Menos de 10 ha & 143 & $34,1 \%$ \\
\hline 10 a 39,9 ha & 102 & $24,3 \%$ \\
\hline 40 ha e mais & 71 & $16,9 \%$ \\
\hline
\end{tabular}

Obs.: exclui dados ignorados. *MF = módulos fiscais conforme critério do Incra (ver site da Embrapa https://www.embrapa.br/ codigo-florestal/area-de-reserva-legal-arl/modulo-fiscal). Em média as propriedades usavam 98,8 ha para agricultura (dp = 364,1) com uma mediana bem menor, de 4,5 ha e uma área máxima de 6.000 ha para essa finalidade produtiva.

A Tabela 2 apresenta a proporção da área da UP destinada a agricultura, criação animal e mata nativa, conforme tamanho da UP. Devido a inconsistências nos dados de área conforme tipo de uso, o número de UP avaliadas foi menor nesta análise $(n=359)$. As maiores proporções de área para agricultura foram identificadas nas médias e grandes UP. Por outro lado, as maiores proporções de área para criação animal foram encontradas, principalmente, nos minifúndios e nas pequenas UP.

Tabela 2 - Proporção de área para agricultura, criação de animais e vegetação nativa conforme tamanho das unidades produtivas (UP) em módulos fiscais (MF)

\begin{tabular}{|c|c|c|c|c|c|}
\hline & $\begin{array}{c}<1 \mathrm{MF} \\
(<25 \mathrm{ha})\end{array}$ & $\frac{1 \text { a } 4 \text { MF }}{\text { (25-100ha) }}$ & $\begin{array}{c}4,1 \text { a } 15 \text { MF } \\
(100,1-375 h a)\end{array}$ & $\begin{array}{c}>15 \text { MF } \\
(>375 h a)\end{array}$ & Total \\
\hline $\mathrm{N}^{\circ}$ amostra/n & 131 & 169 & 72 & 54 & 426 \\
\hline desta análise* & 113 & 139 & 57 & 50 & 359 \\
\hline \multicolumn{5}{|c|}{$\%$ área p/ agricultura } & $p<0,001$ \\
\hline Não relatou & $25(22,1)$ & $21(15,2)$ & $9(16,1)$ & $6(12,2)$ & $61(17,1)$ \\
\hline Até $29 \%$ & $57(50,4)$ & $67(48,6)$ & $17(30,4)$ & $4(8,2)$ & $145(40,7)$ \\
\hline $30 \%$ e mais & $31(27,4)$ & $50(36,2)$ & $30(53,6)$ & $39(79,6)$ & $150(42,1)$ \\
\hline \multicolumn{5}{|c|}{$\%$ da área $\mathrm{p} /$ animais } & $p<0,001$ \\
\hline Não relatou & $15(13,3)$ & $33(23,7)$ & $12(20,7)$ & $26(54,2)$ & $86(24,0)$ \\
\hline Até $60 \%$ & $46(40,7)$ & $43(30,9)$ & $26(44,8)$ & $16(33,3)$ & $131(36,6)$ \\
\hline $61 \%$ e mais & $52(46,0)$ & $63(45,3)$ & $20(34,5)$ & $6(12,5)$ & $141(39,4)$ \\
\hline \multicolumn{5}{|c|}{ \% da área p/ vegetação nativa } & $p=0,18$ \\
\hline Não relatou & $30(26,5)$ & $32(23,0)$ & $13(22,8)$ & $17(34,0)$ & $92(25,6)$ \\
\hline Até 19\% & $36(31,9)$ & $59(42,4)$ & $27(47,4)$ & $13(26,0)$ & $135(37,6)$ \\
\hline $20 \%$ e mais & $47(41,6)$ & $48(34,5)$ & $17(29,8)$ & $20(40,0)$ & $132(36,8)$ \\
\hline
\end{tabular}

Obs.: *exclui dados ignorados ou inconsistentes. MF = módulos fiscais/Incra 
Embora cerca de um quarto dos estabelecimentos $(26,6 \%)$ tenha informado ausência de mata nativa (Tabela 2), alguns tinham uma área considerável, com matas de até 3.000 hectares. Grandes áreas de mata nativa predominavam nas UP com maiores extensões. Contudo, apesar das UP grandes e médias apresentarem as maiores concentrações de mata nativa, ao ser analisada a proporção da área reservada para vegetação nativa não foram encontradas diferenças significativas entre os grupos de MF.

O fato de preservar mata nativa pode ser considerado um fator protetor para os agricultores e para o ambiente, especialmente a água. Estudo realizado por Bortoluzzi et al. (2006) em uma microbacia hidrográfica em Agudo (RS) identificou a presença de princípios ativos de agrotóxicos em lavouras de estreita mata ciliar e nenhum agrotóxico na unidade amostral totalmente coberta com vegetação permanente ou com expressiva mata ciliar.

A Tabela 3 apresenta o tipo de produção agrícola conforme tamanho da UP.

A principal produção agrícola do município eram frutas, produzidas em $31,9 \%$ das UP. Entre elas destaca-se a produção de maçã (13,6\%), mas também pera, caqui, pêssego, ameixa, uva e frutas vermelhas (amora, framboesa, morango e mirtilo). Havia uma considerável produção de hortigranjeiros como batata, cebola, feijão, mandioca, tomate. Além desses, a maioria das UP $(53,5 \%)$ produzia grãos e cereais para comercialização ou para alimentação do gado: milho $(50,7 \%)$, soja $(23,5 \%)$, aveia $(19,2 \%)$ e feijão $(32,9 \%)$, entre outros.

Tabela 3 - Distribuição dos principais tipos de produção agrícola conforme tamanho da unidade produtiva* (UP)

\begin{tabular}{|c|c|c|c|c|c|c|}
\hline \multirow[b]{2}{*}{ Produto } & \multicolumn{5}{|c|}{ Tamanho das UP em módulos fiscais (MF) } & \multirow[b]{2}{*}{ Valor de $p^{\star \star}$} \\
\hline & $\begin{array}{l}<1 \mathrm{MF} \\
\mathrm{n}(\%)\end{array}$ & $\begin{array}{c}1-4 \mathrm{MF} \\
\mathrm{n}(\%)\end{array}$ & $\begin{array}{c}\text { 4,1-15 MF n } \\
(\%)\end{array}$ & $\begin{array}{c}>15 \mathrm{MF} \\
\mathrm{n}(\%)\end{array}$ & $\begin{array}{l}\text { Total } \\
\text { n (\%) }\end{array}$ & \\
\hline Total & 131 & 169 & 72 & 54 & 426 & \\
\hline \multicolumn{7}{|l|}{ Lavoura/pomar } \\
\hline Aipim & $13(9,9)$ & $6(3,6)$ & $1(1,4)$ & $0(0)$ & $20(4,7)$ & $p=0,005$ \\
\hline Amora & $34(26,0)$ & $24(14,2)$ & $2(2,8)$ & $1(1,9)$ & $61(14,3)$ & $p<0,001$ \\
\hline Aveia & $14(10,7)$ & $19(11,2)$ & $20(27,8)$ & $29(53,7)$ & $82(19,2)$ & $p<0,001$ \\
\hline Feijão & $54(41,2)$ & $52(30,8)$ & $16(22,2)$ & $18(33,3)$ & $140(32,9)$ & $p=0,04$ \\
\hline $\begin{array}{l}\text { Framboesa, } \\
\text { mirtilo, } \\
\text { morango }\end{array}$ & $13(9,9)$ & $8(4,7)$ & $2(2,8)$ & $1(1,9)$ & $24(5,6)$ & $p=0,01$ \\
\hline Maçã & $8(6,1)$ & $24(14,2)$ & $14(19,4)$ & $12(22,2)$ & $58(13,6)$ & $p=0,007$ \\
\hline Milho & $68(51,9)$ & $82(48,5)$ & $31(43,1)$ & $35(64,8)$ & $216(50,7)$ & $p=0,09$ \\
\hline $\begin{array}{l}\text { Pêssego, pera } \\
\text { ou ameixa }\end{array}$ & $10(7,6)$ & $10(5,9)$ & $7(9,7)$ & $3(5,6)$ & $30(7,0)$ & $p=0,71$ \\
\hline Soja & $7(5,3)$ & $32(18,9)$ & $28(38,9)$ & $33(61,1)$ & $100(23,5)$ & $p<0,001$ \\
\hline Trigo & $0(0,0)$ & $5(2,9)$ & $10(13,9)$ & $29(53,7)$ & $44(10,3)$ & $p<0,001$ \\
\hline Uva & $18(13,7)$ & $17(10,1)$ & $6(8,3)$ & $3(5,6)$ & $44(10,3)$ & $p=0,07$ \\
\hline \multicolumn{7}{|c|}{ Produção animal } \\
\hline Abelhas & $7(5,3)$ & $23(13,7)$ & $6(8,5)$ & $3(5,8)$ & $39(9,2)$ & $p=0,07$ \\
\hline Aves & $19(14,5)$ & $31(18,5)$ & $17(23,9)$ & $9(17,3)$ & $76(18,0)$ & $p=0,42$ \\
\hline Bovinos & $82(62,6)$ & $115(68,5)$ & $55(77,5)$ & $30(57,7)$ & $282(66,8)$ & $p=0,08$ \\
\hline Equinos & $14(10,7)$ & $28(16,7)$ & $25(35,2)$ & $16(30,8)$ & $83(19,7)$ & $p<0,001$ \\
\hline Ovinos & $7(5,3)$ & $19(11,3)$ & $17(23,9)$ & $8(15,4)$ & $51(12,1)$ & $p=0,001$ \\
\hline Peixes & $2(1,5)$ & $7(4,1)$ & $3(4,2)$ & $0(0,0)$ & $12(2,8)$ & $p=0,27$ \\
\hline Suínos & $21(16,0)$ & $25(14,9)$ & $13(18,3)$ & $11(21,2)$ & $70(16,6)$ & $p=0,71$ \\
\hline $\begin{array}{l}\text { Algum animal } \\
\text { de criação }\end{array}$ & $119(90,8)$ & $141(84,9)$ & $60(83,3)$ & $33(61,1)$ & $353(83,5)$ & $p<0,001$ \\
\hline
\end{tabular}

Obs.: ${ }^{*} \mathrm{n}=$ unidades produtivas com esse produto agrícola; exclui dados ignorados. É possível mais de uma resposta; **teste qui-quadrado/tendência linear 
Comparando conforme área, verificou-se que nas UP menores predominavam produção de aipim e frutas vermelhas, com destaque para a amora. O feijão era bastante produzido nos minifúndios, mas também em outros grupos de área.

Nas UP maiores predominou o cultivo de maçã, cereais e grãos, como aveia, soja e trigo (Tabela 3). As médias e grandes UP apresentaram também maior proporção de cultivo de soja e de maçã, que é o maior destaque na produção agrícola do município. O município é considerado o maior produtor de maçãs do Rio Grande do Sul e $2^{\circ}$ maior do país. ${ }^{1}$

Em relação à pecuária, em 83,5\% das UP havia algum tipo de criação animal (Tabela 3). Em média eram usados 60,4 ha para criação de diferentes tipos de animais $(\mathrm{dp}=231,4)$ com uma mediana de 14 ha e variação máxima até 3.500 ha. A principal produção era de bovinos $(66,8 \%)$, seguida de equinos (19,7\%), aves (18,0\%), suínos (16,6\%), ovinos (12,1\%), além de abelhas e peixes.

Avaliando a produção animal conforme área, verificou-se uma maior proporção de equinos e ovinos nas UP médias e grandes. Parece haver proporção maior de abelhas nas pequenas e de bovinos nas médias UP. Contudo, essas diferenças ficaram além da significância estatística. Não foram verificadas diferenças conforme tamanho da UP em relação aos demais tipos de animais (Tabela 3).

Nas UP maiores também foi verificada uma elevação na proporção dos rebanhos equinos e ovinos, que são animais com maior valor econômico. No caso dos bovinos houve um aumento (não significativo) na proporção de criação nas médias UP. A ausência de diferença relacionada à produção de bovinos pode ser devido ao fato de não ter sido dimensionado o número de cabeças de animais (somente a proporção de estabelecimentos com cada tipo de animal). As UP menores tinham, com maior frequência, alguma criação animal.

Sobre a disponibilidade de máquinas e veículos, observou-se que $72,7 \%$ relataram uso regular de automóveis, quase $70 \%$ usavam máquinas agrícolas (ex.: trator, colheitadeira) e menos da metade (43,2\%) usava algum veículo para transportar produção (Tabela 4). As médias e, principalmente, as grandes UP tinham maiores proporções de estabelecimentos com todos os tipos de veículos e máquinas: automóveis, máquinas agrícolas e, principalmente, veículos para transporte de produção. Todas as que informaram veículos pata transportar produção, também informaram ter alguma máquina agrícola.

Tabela 4 - Distribuição de veículos e máquinas agrícolas segundo tamanho da unidade produtiva (UP)

\begin{tabular}{|c|c|c|c|c|c|c|}
\hline \multirow[b]{2}{*}{ Variáveis } & \multicolumn{5}{|c|}{ Tamanho das UP em módulos fiscais (MF) } & \multirow{2}{*}{$\begin{array}{l}\text { Valor } \\
\text { de } p^{* *}\end{array}$} \\
\hline & $\begin{array}{c}<1 \mathrm{MF} \\
\mathrm{n}(\%)\end{array}$ & $\begin{array}{c}1-4 \mathrm{MF} \\
\mathrm{n}(\%)\end{array}$ & $\begin{array}{c}4,1-15 \\
\text { MF } n(\%)\end{array}$ & $\begin{array}{c}>15 \mathrm{MF} \\
\mathrm{n}(\%)\end{array}$ & $\begin{array}{c}\text { Total } \mathbf{n} \\
(\%)\end{array}$ & \\
\hline Total de UP* & 131 & 169 & 72 & 54 & 426 & \\
\hline \multicolumn{7}{|l|}{ Tem/usa veículos e máquinas agrícolas } \\
\hline Automóvel & $84(64,6)$ & $117(70,1)$ & $59(86,8)$ & $43(82,7)$ & $303(72,7)$ & 0,003 \\
\hline Máquina agrícola & $65(49,6)$ & $119(71,7)$ & $56(80,0)$ & $53(100,0)$ & $293(69,8)$ & $<0,001$ \\
\hline Veículo p/ transportar produção & $45(34,9)$ & $62(37,8)$ & $33(51,6)$ & $36(72,0)$ & $176(43,2)$ & $<0,001$ \\
\hline \multicolumn{7}{|c|}{ Equipamentos para aplicação de agrotóxicos e outros produtos } \\
\hline Trator - cabine fechada + filtro químico & $1(0,8)$ & $12(7,2)$ & $11(15,7)$ & $22(42,3)$ & $46(11,1)$ & $<0,001$ \\
\hline Trator turbo-atomizador & $10(8,0)$ & $25(15,1)$ & $13(18,6)$ & $14(26,9)$ & $62(15,0)$ & 0,003 \\
\hline Pulverizador barra e motor estacionário & $15(12,9)$ & $25(15,2)$ & $21(31,3)$ & $17(34,0)$ & $78(19,6)$ & $<0,001$ \\
\hline Pulverizador costal-manual ou mecanizado & $78(67,2)$ & $111(67,3)$ & $29(43,3)$ & $7(14,0)$ & $225(56,5)$ & $<0,001$ \\
\hline Usa seringa (no rebanho) & $38(30,4)$ & $65(39,2)$ & $19(27,1)$ & $7(13,5)$ & $129(31,2)$ & 0,002 \\
\hline Nível de mecanização ( $n$ = 397) & & & & & & $<0,001$ \\
\hline Baixo & $54(43,9)$ & $39(24,1)$ & $13(20,6)$ & $1(2,0)$ & $107(27,0)$ & \\
\hline Médio & $34(27,6)$ & $60(37,0)$ & $17(27,0)$ & $10(20,4)$ & $121(30,5)$ & \\
\hline Alto & $35(28,5)$ & $63(38,9)$ & $33(52,4)$ & $38(77,6)$ & $169(42,6)$ & \\
\hline
\end{tabular}

Obs.: *exclui dados ignorados. É possível mais de uma resposta; **teste qui-quadrado/tendência linear

1 Disponível em https://www.vacaria.rs.gov.br/vacaria/dados-gerais 
Examinando os equipamentos usados para aplicação de agrotóxicos, observa-se um padrão claro na distribuição das UP conforme tamanho. Os equipamentos de maior custo são mais usados nas médias e grandes. Entre estes destacam-se os tratores com cabines fechada, climatizada e filtro mecânico e químico, que reduz bastante o risco para o trabalhador. Os pulverizadores costais (quase todos do tipo manual) eram usados pela maioria das UP (Tabela 4), com a maior proporção de uso desses pulverizadores localizada nos minifúndios e pequenas UP, que tinham quase três vezes a proporção dos grandes estabelecimentos rurais. Esses equipamentos são identificados com maior exposição ocupacional aos agrotóxicos e usualmente são de menor custo.

Além desses equipamentos, em 129 UP $(31,2 \%)$ eram usadas seringas para aplicação de inseticidas e/ou parasiticidas no gado (Tabela 4). Outros "equipamentos" de aplicação de agrotóxicos menos comuns foram avião (3 UP) e banheira para gado (6 UP). O uso de trator com cabine fechada e filtro químico era mais comum em grandes, seguido das médias UP ( $p<$ 0,001 ). Padrão semelhante ocorreu com trator com turboatomizador. No caso de pulverizadores com motor estacionário predominavam de forma equilibrada as médias e grandes UP. Os pulverizadores costais, manuais na sua grande maioria, eram mais usados em UP menores e com menor nível de mecanização $(p<0,001)$.

A análise do nível de mecanização conforme tamanho da UP revelou diferenças claras entre os grupos: a proporção de UP com baixa mecanização era mais frequente nos minifúndios. Nas pequenas predominava o nível médio e nas médias e grandes havia um nível maior de mecanização (Tabela 4).

A disponibilidade de máquinas e/ou veículos agrícolas é considerada indicador econômico e de nível de mecanização do estabelecimento (Instituto Brasileiro de Geografia e Estatística, 2017). A presença de maior proporção de UP com máquinas agrícolas e veículos para transporte de produção indica que as maiores UP teriam um nível maior de mecanização, com predomínio absoluto do uso de trator, em especial aqueles com cabine fechada e filtro químico, úteis para reduzir exposição do trabalhador aos agrotóxicos. Essa heterogeneidade tecnológica entre grandes e pequenas propriedades repete-se entre diferentes regiões brasileiras. Souza et al. (2019) destacam que a desigualdade e seus consequentes níveis de exclusão resultam, em parte, da "desigualdade com que foram distribuídos os benefícios decorrentes das políticas implementadas" (p. 596), entre elas a de crédito rural. Para Sampaio \& Fredo (2021), com base nos estudos de Santos \& Vieira Filho (2012), as culturas ou produtos agrícolas que se inserem em cadeia de produção moderna experimentam condições de articulação, de acesso a tecnologias, a créditos e outros instrumentos de produtividade e renda, enquanto culturas com restrita integração ficam à margem dos investimentos e incentivos tecnológicos. O resultado é a convivência entre áreas rurais pobres e outras com intensa geração de renda e riqueza.

Em relação ao uso de agrotóxicos, 408 UP (96,5\%) informaram uso regular e cerca de 86,5\% relataram ter usado esses produtos nos últimos 30 dias (Tabela 5). Entre esses destacavamse os inseticidas organofosforados, piretroides, fipronil, amitraz e neonicotinoides. Também eram bastante usados os fungicidas triazois, estrobilurina, ditiocarbarmatos, benzimidazol e dicarboximidas. Os herbicidas de uso mais frequente eram as triazinas, glifosato, glufosinato de amônio, paraquate e 2,4-D. Também foi informado o uso de reguladores de crescimento, como cianamida. Foram informados vários produtos veterinários como vermífugos, vacinas, vitaminas e outros medicamentos. Também foi relatado uso de produtos químicos como desinfetantes, fertilizantes, tratamentos de sementes e outros.

Para examinar a forma de armazenamento e o descarte de embalagens excluem-se do cálculo as UP que não usavam agrotóxicos (cerca da 3,5\%) e aquelas com informação ignorada. As UP 
maiores apresentaram maior proporção de locais adequados de armazenamento, alcançando $63,5 \%$ nas grandes (Tabela 5). O armazenamento em galpões, junto a outros produtos agrícolas foi mais frequente em minifúndios e pequenas UP. Nenhuma grande UP relatou armazenar embalagem na propriedade. Em 11 estabelecimentos não havia local de armazenamento: os entrevistados relataram receber a quantidade de agrotóxicos para uma única aplicação, a ser usada no mesmo dia da entrega.

Tabela 5 - Distribuição do local de armazenamento e destino de embalagens de agrotóxicos usados na agricultura e na pecuária segundo tamanho da UP

\begin{tabular}{|c|c|c|c|c|c|c|}
\hline \multirow[b]{2}{*}{ Gestão de agrotóxicos } & \multicolumn{5}{|c|}{ Tamanho das UP em módulos fiscais (MF) } & \multirow{2}{*}{$\begin{array}{l}\text { Valor de } \\
\qquad p^{\star \star}\end{array}$} \\
\hline & $\begin{array}{l}<1 \mathrm{MF} \\
\mathrm{n}(\%)\end{array}$ & $\begin{array}{l}1-4 \mathrm{MF} \\
\mathrm{n}(\%)\end{array}$ & $\begin{array}{l}4,1-15 \mathrm{MF} \\
\mathrm{n}(\%)\end{array}$ & $\begin{array}{c}>15 \mathrm{MF} \\
\mathrm{n}(\%)\end{array}$ & $\begin{array}{c}\text { Total n } \\
(\%)\end{array}$ & \\
\hline $\mathrm{N}$ total/ & $131 /$ & $169 /$ & 721 & $54 /$ & $426 /$ & \\
\hline N2* & 101 & 134 & 55 & 26 & 316 & \\
\hline Utiliza agrotóxicos & $122(93,1)$ & $167(99,4)$ & $68(95,8)$ & $51(96,2)$ & $408(96,5)$ & 0,04 \\
\hline $\begin{array}{l}\text { Utilizou nos últimos } 30 \text { dias } \\
\text { Local de armazenagem }\left(\mathrm{N}^{2}\right)\end{array}$ & $92(75,4)$ & $147(88,0)$ & $64(94,1)$ & $50(98,0)$ & $353(86,5)$ & $<0,001$ \\
\hline $\begin{array}{l}\text { Em casa, porão, armário, } \\
\text { etc.) }\end{array}$ & $18(14,9)$ & $26(15,8)$ & $10(14,7)$ & $7(13,5)$ & $65(15,0)$ & 0,98 \\
\hline $\begin{array}{l}\text { Depósito trancado p/ prod. } \\
\text { químico }\end{array}$ & $24(19,8)$ & $56(33,9)$ & $36(52,9)$ & $33(63,5)$ & $113(26,8)$ & $<0,001$ \\
\hline Galpão & $53(40,8)$ & $45(27,1)$ & $12(16,9)$ & $3(5,6)$ & $113(26,8)$ & $<0,001$ \\
\hline Local ext. c/ outros prod. & $24(18,5)$ & $32(19,3)$ & $7(9,9)$ & $6(11,1)$ & $69(16,4)$ & 0,04 \\
\hline Não guarda na UP & $2(1,6)$ & $4(2,4)$ & $2(2,9)$ & $3(5,8)$ & $11(2,7)$ & 0,48 \\
\hline \multicolumn{7}{|c|}{ Destino de embalagens - agricultura (N2) } \\
\hline Deixa no campo/ arroio & $2(2,4)$ & $1(0,8)$ & $0(0,0)$ & $0(0,0)$ & $3(1,0)$ & 0,45 \\
\hline Enterra & $6(7,1)$ & $3(2,5)$ & $1(1,9)$ & $2(4,3)$ & $12(3,9)$ & 0,33 \\
\hline Queima & $29(34,1)$ & $40(33,1)$ & $8(15,4)$ & $2(4,3)$ & $79(26,0)$ & $<0,001$ \\
\hline Aracamp ${ }^{(a)}$ & $29(34,1)$ & $57(47,1)$ & $31(59,6)$ & $41(89,1)$ & $158(52,0)$ & $<0,001$ \\
\hline Lixo tóxico & $11(12,9)$ & $11(9,1)$ & $3(5,8)$ & $3(6,5)$ & $28(9,2)$ & 0,46 \\
\hline Guarda na UP & $11(12,9)$ & $13(10,7)$ & $3(5,8)$ & $0(0,0)$ & $27(8,9)$ & 0,008 \\
\hline Lixo comum & $3(3,5)$ & $1(0,8)$ & $1(1,9)$ & $0(0,0)$ & $5(1,6)$ & 0,37 \\
\hline \multicolumn{7}{|c|}{ Destino de embalagens - pecuária (N2) } \\
\hline Deixa no campo/arroio & $2(2,0)$ & $2(1,5)$ & $1(1,8)$ & $0(0,0)$ & $5(1,6)$ & 0,91 \\
\hline Enterra & $13(12,9)$ & $18(13,3)$ & $6(10,9)$ & $8(30,8)$ & $45(14,2)$ & 0,09 \\
\hline Queima & $42(41,6)$ & $53(39,6)$ & $14(25,5)$ & $7(26,9)$ & $116(36,7)$ & 0,04 \\
\hline Aracamp $^{(a)}$ & $5(5,0)$ & $3(2,2)$ & $8(14,5)$ & $2(7,7)$ & $18(5,7)$ & 0,01 \\
\hline Lixo tóxico & $12(11,9)$ & $13(9,7)$ & $8(14,5)$ & $2(7,7)$ & $35(11,0)$ & 0,73 \\
\hline Guarda na UP & $17(16,8)$ & $32(23,9)$ & $11(20,0)$ & $0(0,0)$ & $60(19,0)$ & 0,04 \\
\hline Lixo comum & $9(8,9)$ & $6(4,5)$ & $2(3,6)$ & $3(11,5)$ & $20(6,3)$ & 0,29 \\
\hline Outro destino & $3(2,9)$ & $7(5,2)$ & $9(16,4)$ & $4(15,4)$ & $23(7,3)$ & 0,005 \\
\hline
\end{tabular}

Obs.: *N2: n desta análise; exclui dados ignorados. É possível mais de uma resposta; **teste qui-quadrado/tendência linear. (a) Aracamp é central de recolhimento dessas embalagens

Nos minifúndios e pequenas UP foi observado um predomínio de destinação inadequada das embalagens como enterrar, queimar, guardar em casa ou descartar como resíduo comum. O local recomendado para recolhimento, a Central de Recolhimento de Embalagens de Agrotóxicos (Aracamp), predominou nas médias e principalmente nas grandes UP, onde chegava a $89,1 \%$ para as embalagens usadas na agricultura.

Por outro lado, em relação aos produtos veterinários, muitos quimicamente idênticos aos produtos usados na agricultura, esse percentual de recolhimento de embalagens não chegava a 
8\%. Além disso, nas embalagens para pecuária observou-se aumento da proporção de enterrar, guardar ou dar outros destinos. Embora queimar embalagens para pecuária predomine entre as menores UP, a proporção que admitiu essa prática também foi bem importante entre as maiores. Foram identificadas 70 UP $(16,6 \%)$ que relataram não usar produtos veterinários. Entre as demais, embora existissem diferenças na destinação dessas embalagens, em todos os tamanhos de UP a destinação adequada corresponde a uma pequena parte.

O modelo de produção desse município se mostra vinculado ao uso frequente de produtos químicos como agrotóxicos e produtos veterinários, com mais de $95 \%$ das UP relatando uso regular desses produtos, sendo apenas um pouco menor nos minifúndios. Esses resultados são consistentes com o Censo Agro 2017, que também verificou aumento no uso de agrotóxicos tanto na agricultura familiar como na não familiar (Instituto Brasileiro de Geografia e Estatística, 2017). ${ }^{2}$

Apesar de apresentar um olhar panorâmico sobre as práticas envolvendo o uso de agrotóxicos, uma limitação deste estudo foi não ter mensurado a quantidade de agrotóxicos usada nas UP, que podem ser volumosas em grandes e médias produções agrícolas como soja e/ou maçã. Ou seja, apesar dessas UP maiores apresentarem maior percentual de práticas recomendadas para uso de agrotóxicos, a exposição ambiental e ocupacional pode ser importante devido ao uso mais intensivo nessas. Outra razão para se examinar com cautela estes resultados é a elevada proporção de dados ignorados nesse bloco, expressa na Tabela 5 como N2. Observase que a proporção de respostas válidas caiu para menos da metade no caso das grandes UP. Não está clara a razão dessas respostas ignoradas nesse bloco e nem como essas ausências de resposta influenciaram nos resultados.

Sobre o uso intensivo de agrotóxicos este estudo foi consistente com outro realizado na Serra Gaúcha (Faria et al., 2000) que também encontrou 95\% das UP com uso regular desses produtos. O uso intenso de agrotóxicos evidencia uma agricultura cada vez mais dependente de insumos químicos. Devido aos impactos na saúde e no meio ambiente e devido ao crescimento da resistência das pragas, esse modelo de produção tem sido criticado por quem defende um modelo sustentável de desenvolvimento agrícola. Carneiro et al. (2015) chamaram atenção ao fato de que o consumo médio de agrotóxicos vem aumentando em relação à área plantada: passou de 10,5 litros/ha em 2002 para 12 litros/ha em 2011. Cabe destacar que a aveia, a maçã e a soja são culturas plantadas principalmente em médias e grandes UP e usualmente isso inclui a aplicação de agrotóxicos várias vezes em uma mesma safra.

O tipo de equipamento usado para aplicação dos agrotóxicos, o uso de depósitos trancados e específicos para produtos químicos, bem como o destino de embalagens na agricultura sugerem um risco mais elevado para os agricultores de minifúndios e pequenas UP, devido à maior frequência de uso de pulverizadores costais e práticas menos seguras na gestão desses produtos. Em outra direção, o estudo identificou nas médias e grandes UP uma proporção mais elevada de aplicação de agrotóxicos usando trator com cabine fechada e filtro químico. Além de ser mais confortável, reduz o risco químico do trabalhador.

A maioria das maiores UP relatou uso de depósitos trancados para armazenamento dos agrotóxicos (Tabela 5). Contudo, apesar de maior que nas UP menores, essa proporção (52,7\% nas médias e 63,5\% nas grandes) está longe do recomendado pela Norma Regulamentadora de Segurança e Saúde no Trabalho da Agricultura - NR (NR 31/revisada em 2020), ${ }^{3}$ que no item 31.7.14 estabelece a exigência - para todos os estabelecimentos com uso de agrotóxicos - de armazenar esses produtos em edificações sólidas, fechadas, longe de fontes de água, de alimentos

\footnotetext{
2 IBGE. Censo Agropecuário 2017. Resultados definitivos (acessado em: 18/07/2021, disponível em https://biblioteca. ibge.gov.br/visualizacao/periodicos/3096/agro_2017_resultados_definitivos.pdf) Rio de Janeiro: Instituto Brasileiro de Geografia e Estatística-IBGE 2019

3 https://www.in.gov.br/en/web/dou/-/portaria-n-22.677-de-22-de-outubro-de-2020-285009351
} 
e de edificações habitadas, além do acesso restrito aos trabalhadores com treinamento para esses produtos. Ou seja, existe ainda um número considerável de UP de todos os tamanhos que necessitam melhorar o sistema de armazenamento dos agrotóxicos.

Nos estabelecimentos menores, além de apenas 36\% apresentarem destino correto de embalagens, foi documentada uma frequência maior de práticas ambientalmente incorretas como enterrar, queimar ou guardar. Conforme Carneiro et al. (2015), a antiga prática de enterrar as embalagens de agrotóxicos é condenada devido aos altos riscos de contaminação do solo e das águas subterrâneas. Os resíduos presentes em embalagens, quando abandonados no ambiente ou descartados em aterros e lixões, contaminam o solo e, sob a ação da chuva, são carreados para águas superficiais e subterrâneas.

Mesmo sendo um tema debatido e regulamentado, as embalagens vazias de agrotóxicos continuam a ser descartadas de forma irregular, sem controle e fiscalização adequados. O Censo Agropecuário de 2006, conforme Carneiro et al. (2015), registrou que metade dos estabelecimentos não apresentava destino adequado do seu "lixo" tóxico e evidenciou a desigualdade sociorregional em relação às embalagens dos agrotóxicos. Por exemplo, enquanto Alagoas, Sergipe e Bahia queimavam a maioria das embalagens (63,3\%, 53,6\% e 55,7\%), na região Sul esse percentual não atingia os $10 \%$. Os resíduos incluem restos de agrotóxicos, embalagens vazias e produtos contaminados com os agrotóxicos. Importante destacar que o Censo Agropecuário de 2017 suprimiu as questões relativas a esse tema. Ou seja, não será possível avaliar possíveis avanços (ou retrocessos) em relação ao destino de embalagens de agrotóxicos por não haver dados para comparação.

Dessa forma, a desigualdade na destinação correta de embalagens conforme tamanho das UP (e padrão agroeconômico) seria comparável às desigualdades sociorregionais brasileiras com pior situação nos estados do Norte e Nordeste (Carneiro et al., 2015). Da mesma forma que a desigualdade econômica identificada entre as UP de Vacaria, as regiões no Brasil com maior carência socioeconômica apresentam piores índices em relação ao descarte de embalagens, acentuando a vulnerabilidade dessas populações. Preza \& Augusto (2012), ao estudar os riscos de trabalhadores rurais na Bahia, revelam um quadro de fragilidade social e de exposição ambiental e humana aos agrotóxicos. Ressaltam ainda as condições de riscos relacionados a agrotóxicos no Nordeste.

As embalagens de produtos veterinários mostraram um padrão bem diferente do que o destino das embalagens usadas na agricultura, com uma proporção média de destinação correta (central de reciclagem) inferior a 6\%. Essa diferença ocorre porque produtos veterinários não estão incluídos de forma explícita na legislação sobre agrotóxicos. Na mesma direção, o Dossiê Abrasco (Carneiro et al., 2015) alertou para a invisibilidade dos riscos do uso de agrotóxicos para fins veterinários. Silva et al. (2012) alertaram sobre a existência de 7.222 produtos veterinários autorizados para comercialização no país, com destaque para os antibióticos e os produtos de combate aos ectoparasitas. Esses produtos são regulados exclusivamente pelo Ministério da Agricultura, Pecuária e Abastecimento (MAPA) e, através de brechas na legislação de agrotóxicos, os produtores não se sentem submetidos às mesmas exigências em relação ao destino das embalagens.

Examinando as orientações técnicas para o uso de agrotóxicos e produtos veterinários, verificou-se que $25,7 \%$ não recebia nenhuma orientação técnica, sendo esse percentual bem maior nos minifúndios e nas pequenas UP (Tabela 6). A proporção de UP que recebia orientação técnica era superior a $80 \%$ nos médios e grandes estabelecimentos, enquanto cerca de 30\% dos responsáveis por UP menores afirmaram não receber orientações técnicas 
de nenhum tipo. O vendedor da loja era quem orientava quase $30 \%$ das UP, com predomínio nos minifúndios.

Tabela 6 - Distribuição da existência de orientações técnicas para uso de agrotóxicos conforme tamanho da unidade produtiva (UP)

\begin{tabular}{|c|c|c|c|c|c|c|}
\hline \multirow[b]{2}{*}{ Variáveis } & \multicolumn{5}{|c|}{ Tamanho das UP em módulos fiscais (MF)* } & \multirow{2}{*}{$\begin{array}{c}\text { Valor de } \\
p^{*}\end{array}$} \\
\hline & $\begin{array}{l}<1 \mathrm{MF} \\
\mathrm{n}(\%)\end{array}$ & $\begin{array}{l}1-4 \mathrm{MF} \\
\mathrm{n}(\%)\end{array}$ & $\begin{array}{c}4,1-15 \\
\text { MF n (\%) }\end{array}$ & $\begin{array}{l}>15 \mathrm{MF} \\
\mathrm{n}(\%)\end{array}$ & $\begin{array}{c}\text { Total } n \\
(\%)\end{array}$ & \\
\hline Total de UP & 131 & 169 & 72 & 54 & 426 & \\
\hline \multicolumn{7}{|c|}{ Recebe orientações técnicas sobre agrotóxicos } \\
\hline Nenhuma orientação & $36(29,8)$ & $52(31,5)$ & $13(19,1)$ & $3(5,9)$ & $104(25,7)$ & 0,001 \\
\hline Recebe alguma orientação & $85(70,2)$ & $113(68,5)$ & $55(80,9)$ & $48(94,1)$ & $301(74,3)$ & 0,001 \\
\hline Vendedor da loja & $52(39,7)$ & $49(29,0)$ & $19(26,4)$ & $7(13,0)$ & $127(29,8)$ & $<0,001$ \\
\hline Do dono & $4(3,1)$ & $9(5,3)$ & $4(5,6)$ & $7(13,0)$ & $24(5,6)$ & 0,02 \\
\hline Vizinho/amigo & $4(3,1)$ & $3(1,8)$ & $2(2,8)$ & $0(0,0)$ & $9(2,1)$ & 0,58 \\
\hline Técnicos da Emater & $11(8,4)$ & $15(8,9)$ & $2(2,8)$ & $1(1,9)$ & $29(6,8)$ & 0,04 \\
\hline Agrôn./técn. contratado & $7(5,3)$ & $19(11,2)$ & $14(19,4)$ & $17(31,5)$ & $57(13,4)$ & $<0,001$ \\
\hline $\begin{array}{l}\text { Agrônomo/ técnico da } \\
\text { empresa }\end{array}$ & $5(3,8)$ & $15(8,9)$ & $13(18,1)$ & $16(29,6)$ & $49(11,5)$ & $<0,001$ \\
\hline Veterinário & $5(3,8)$ & $6(3,6)$ & $5(6,9)$ & $1(1,9)$ & $17(4,0)$ & $0,50^{\prime}$ \\
\hline $\begin{array}{l}\text { Algum agrôn. /téc. } \\
\text { agrícola/ veterinário }\end{array}$ & $28(21,4)$ & $54(32,0)$ & $33(45,8)$ & $35(64,8)$ & $150(35,2)$ & $<0,001$ \\
\hline \multicolumn{7}{|c|}{ Observa se agrotóxico é recomendado para a cultura } \\
\hline Sim, sempre & $116(98,3)$ & $157(96,3)$ & $60(92,3)$ & $51(98,1)$ & $384(96,5 \%)$ & 0,18 \\
\hline
\end{tabular}

Obs.: exclui dados ignorados. É possível mais de uma resposta; *teste qui-quadrado/tendência linear

Os agrônomos e técnicos da Emater foram citados como fonte de orientação técnica por menos de $10 \%$, sendo na maior parte dos casos minifúndios e pequenas UP. Por outro lado, a proporção de UP que recebia orientação de agrônomos/técnicos, da empresa ou contratados, era maior nos estabelecimentos médios e grandes. Não foram observadas diferenças conforme tamanho da UP em relação às orientações de veterinários.

Ao se agruparem as orientações recebidas de todos os profissionais técnicos da área agrícola (agrônomos e técnicos agrícolas, de todos os vínculos, bem como os veterinários) verificouse que, em média, 35,2\% das UP tinham acesso a orientações desse tipo de profissional, aumentando à medida em que aumentava o tamanho da UP.

Ao serem questionados se levavam em conta para qual tipo de cultura se aplicava o agrotóxico, $96,5 \%$ dos entrevistados relataram seguir rigorosamente as orientações, não sendo observadas diferenças por tamanho de UP, conforme mostra a Tabela 6 .

Ao analisar os determinantes para utilização de assistência técnica por agricultores familiares no Brasil, Rocha Júnior et al. (2019) evidenciaram que o perfil socioeconômico, as características produtivas e a localização do agricultor afetam a probabilidade de utilização de assistência técnica. Os determinantes: pele não branca, comercialização direta ao consumidor, idade avançada, ser cessionário, baixa escolaridade ou renda per capita reduzem a probabilidade de uso da assistência técnica. Muitos desses determinantes estão presentes na amostra de agricultores deste estudo. 0 mesmo estudo encontrou que $43 \%$ dos agricultores familiares da região Sul e 16,59\% do Brasil recebem assistência, enquanto neste estudo 74,3\% afirmam receber alguma orientação e 25,7 afirmam não receber nenhuma.

Com relação aos produtos agrícolas cultivados, a soja e a maçã, com produção maior nas grandes UP conforme Tabela 4, são produtos mais relacionados com aumento de 
renda agrícola, e a presença nas UP maiores é consistente com os resultados relativos a máquinas e veículos agrícolas, bem como automóveis. Destaca-se também que, dentro do modelo de produção agrícola predominante, recomendado inclusive nos manuais da Embrapa (Embrapa, 2004; Fioravanço \& Santos, 2013) e pelo agronegócio exportador, na produção da maçã e da soja, entre outros, têm sido utilizados grandes volumes de diversos tipos de agrotóxicos.

De forma geral, os dados deste estudo mostram que há situações de risco profissional e ambiental ligadas ao uso intensivo de agrotóxicos. Os grupos com situação de maior vulnerabilidade socioambiental predominavam nas menores UP que, além de apresentarem exposição química importante, recebiam menos orientações técnicas sobre o manejo de riscos. Porém, deve-se destacar que essa avaliação considerou somente alguns parâmetros, sem dispor de um detalhamento de quantidades ou concentrações dos produtos químicos usados. Também não foram coletadas as quantidades da produção agrícola, vegetal ou animal. Algumas dessas UP tinham produtos de agroindústria, que podem acrescentar renda e riscos, mas também não foram mensurados. Acrescenta-se a proporção de dados ignorados em relação ao bloco de questões sobre agrotóxicos. Assim, deve-se reconhecer a existência de riscos elevados nas UP menores. Mas isso não significa que nas maiores não tenham sido documentados riscos importantes. Mesmo com melhores indicadores de manejo dos agrotóxicos, as maiores (médias e grandes) também tinham uma proporção considerável de práticas inadequadas. E provavelmente usavam um volume maior desses produtos químicos, o que pode gerar um aumento da exposição química.

O estudo foi desenvolvido a partir de amostra ampla, vários cuidados metodológicos e de informações fornecidas pelo principal operador da UP. Embora seja um método validado em diversos estudos, a informação referida tem limitações que podem ter influenciado em algumas questões. E o fato de muitos entrevistadores conhecerem parte dos entrevistados pode ter influenciado em alguns registros. Por exemplo, mais de $95 \%$ informaram observar rigorosamente para qual tipo de cultura se aplica o agrotóxico (que é a resposta "correta" a partir dos treinamentos). Contudo, pouco mais de um terço (35\%) relatou ter recebido orientação de algum técnico, agrônomo ou veterinário. E cerca de $25 \%$ afirmaram não receber nenhuma orientação, o que levanta dúvidas sobre como estariam seguindo rigorosamente instruções, se não as recebiam.

Durante o trabalho de campo foram identificadas várias famílias que moravam dentro de grandes pomares de maçã e nas lavouras de grãos. Somente em uma microárea, por exemplo, foram identificadas 26 famílias moradoras, constantemente expostas às derivas de pulverizações. Ou seja, familiares de trabalhadores agrícolas, incluindo crianças, idosos, grávidas e pessoas doentes, são expostos com frequência aos agrotóxicos. Embora não tenham sido mensurados os riscos desse grupo específico, presumem-se efeitos danosos agudos e crônicos devido a essa exposição química ambiental, que em algumas pessoas poderia se sobrepor a outras formas de exposição como a ocupacional, alimentar e/ou ingestão de água com resíduos. Assim, este estudo faz um alerta para a urgente necessidade de definir uma legislação clara sobre a distância mínima entre locais com pulverizações de agrotóxicos e locais habitados. Simultaneamente, o estudo destaca prioridades de ação para as entidades interessadas na proteção da saúde dos trabalhadores e da população rural.

Por fim destaca-se que a preocupação com os impactos do uso intensivo de agrotóxicos tem estimulado a busca por novos modelos de produção agrícola. Têm crescido formas variadas de produção orgânica, não apenas nas UP menores, com algumas experiências bem-sucedidas de agricultura ecológica, mas também em grandes empresas de agronegócio 
que estão investindo em produção orgânica, em cultivos como soja (Pereira et al., 2021) e frutas, como maçã, buscando certificação dessas formas mais sustentáveis de produção agrícola.

\section{CONCLUSÕES}

Os dados mostram que existem muitos aspectos a serem melhorados nos processos produtivos e destacam as diferenças entre as unidades de produção agrícola conforme a área: nas UP maiores predominam as culturas da maçã, cereais e grãos (aveia, soja e trigo), que costumam receber grandes quantidades de agrotóxicos ou várias aplicações, como é o caso da maçã. Por outro lado, as UP maiores apresentam maior proporção de locais recomendados ao armazenamento de agrotóxicos e ao destino adequado das embalagens usadas na agricultura. Essas UP maiores também dispõem de melhor infraestrutura de máquinas agrícolas e veículos de transporte da produção, evidenciando maior nível de mecanização, assim como de equipamentos utilizados para a aplicação do agrotóxico, com menor risco para o trabalhador. No entanto, esse risco diminuído não se estende aos familiares que moram no meio das áreas de cultivo das UP - com exposição frequente por deriva e com risco de desenvolver intoxicações agudas e crônicas.

A dimensão da mata nativa existente nas UP médias e grandes é maior, o que seria considerado um fator de proteção para a saúde e meio ambiente. Porém, não se verificaram diferenças, na proporção de área destinada a mata nativa entre as UP conforme seu tamanho. Assim, em todos os tamanhos de UP ainda existem muitos aspectos que devem melhorar, visando reduzir a contaminação humana e ambiental e isso inclui mais orientações técnicas sobre os produtos e formas de aplicação.

As UP menores armazenam mais agrotóxicos em galpões junto com outros produtos e apresentaram maior proporção de destino inadequado das embalagens (enterrar, queimar, desprezar no lixo comum ou guardar em casa). Esses agricultores estão em situação de maior vulnerabilidade, tanto por possuírem menor nível de mecanização (como trator com cabine e filtro químico), como pela maior exposição ocupacional (a maioria usa pulverizadores costais).

Cabe destacar que, quanto às embalagens de produtos veterinários, não houve diferença significativa entre unidades de produção agrícola maiores e menores. Isso evidencia uma diferença importante na legislação brasileira e nas instituições que fiscalizam o uso de agrotóxicos, revelando uma preocupação menor com resíduos de agrotóxicos provenientes da criação de animais.

Este estudo evidenciou inadequações no manejo de agrotóxicos para o ambiente e para a saúde humana, considerando o tamanho das propriedades. As UP maiores utilizam um grande volume de agrotóxicos e, por outro lado, as menores estão susceptíveis a maior insegurança química no processo de trabalho. Esses agricultores, bem como a população rural que reside próximo das áreas de produção agrícola, permanecem cotidianamente expostos a situações de vulnerabilidade socioambiental (Preza \& Augusto, 2012) que devem ser levadas em conta quando da definição de políticas públicas para o uso de agrotóxicos.

Algumas limitações deste estudo devem ser consideradas em futuros estudos, destacando-se a importância de quantificar de forma mais precisa o volume de agrotóxicos usados nas UP e de avaliar outras formas de exposição química além da pulverização, mensurando também contaminações do solo, ar e água. Além disso, futuros estudos deveriam melhorar a informação de indicadores econômicos, incluindo volume de produção agrícola, desenvolvendo instrumentos para avaliar de forma sintética e mais precisa o nível 
tecnológico de produção agrícola. Que pode incluir outros referenciais do conceito de nível tecnológico, como por exemplo a sustentabilidade, de forma a colaborar na elucidação dessa problemática complexa.

\section{REFERÊNCIAS}

Araujo, I. M. M., \& Oliveira, A. G. R. C. (2017). Agronegócio e agrotóxicos: impactos à saúde dos trabalhadores agrícolas no nordeste brasileiro. Revista Trabalho, Educação e Saúde, 15(1), 117-129. Recuperado em 19 de maio de 2019, de: http://www.scielo.br/scielo. php?script=sci_arttext\&pid=S1981-77462017000100117\&Ing=en\&nrm=iso.

Bombardi, L. M. (2017). Geografia do uso de agrotóxicos no Brasil e conexões com a União Europeia. São Paulo: FFLCH-USP.

Bonita, R., Beaglehole, R., \& Kjellström, T. (2010). Epidemiologia Básica (2. ed, 213 p). Recuperado em 22 de julho de 2021, de: http://apps.who.int/iris/bitstream/ handle/10665/43541/9788572888394_por.pdf;jsessionid=9DEA2197F11 F55C74440832E2 B58F83B?sequence $=5$

Bortoluzzi, E. C., Rheinheimer, D. B., Gonçalves, C. S., Pellegrini, J. B. R., Zanella, R., \& Copetti, A. C. C. (2006). Contaminação de águas superficiais por agrotóxicos em função do uso do solo numa microbacia hidrográfica de Agudo (RS). Revista Brasileira de Engenharia Agrícola e Ambiental, 10(4), 881-887. Recuperado em 09 de março de 2020, de: http://www.scielo.br/ scielo.php?script=sci_arttext\&pid=S1415-43662006000400015\&lng=pt\&nrm=iso.

Brasil. (1989). Lei n 7802, de 11 de julho de 1989. Dispõe sobre a pesquisa, a experimentação, a produção, a embalagem e rotulagem, o transporte, o armazenamento, a comercialização, a propaganda comercial, a utilização, a importação, a exportação, o destino final dos resíduos e embalagens, o registro, a classificação, o controle, a inspeção e a fiscalização de agrotóxicos, seus componentes e afins, e dá outras providências. Recuperdado em 08 de setembro de 2017, de http://www.planalto.gov.br/ccivil_03/leis/l7802.htm

Brasil. (1993). Lei Federal no 8.629, de 25 de fevereiro de 1993. Dispõe sobre a regulamentação dos dispositivos constitucionais relativos à reforma agrária, previstos no Capítulo III, Título VII, da Constituição Federal. Recuperado em 02 de fevereiro de 2020, de http://www.planalto. gov.br/ccivil_03/LEIS/L8629.htm.

Brasil. (2002). Decreto $n^{\circ}$ 4074, de 04 de janeiro de 2002. Regulamenta a Lei 7802 de 11 de julho de 1989. Regulamenta a Lei no 7.802, de 11 de julho de 1989, que dispõe sobre a pesquisa, a experimentação, a produção, a embalagem e rotulagem, o transporte, 0 armazenamento, a comercialização, a propaganda comercial, a utilização, a importação, a exportação, o destino final dos resíduos e embalagens, o registro, a classificação, o controle, a inspeção e a fiscalização de agrotóxicos, seus componentes e afins, e dá outras providências . Recuperado em 05 de setembro de 2018, de http://www.planalto.gov.br/ ccivil_03/decreto/2002/d4074.

Brasil. Ministério da Saúde. (2006). Secretaria de Atenção à Saúde. Protocolo de Atenção à Saúde dos Trabalhadores Expostos a Agrotóxicos. Recuperado em 11 de março de 2020, de https:// bvsms.saude.gov.br/bvs/publicacoes/protocolo_atencao_saude_trab_exp_agrotoxicos.pdf

Brasil. Ministério da Saúde. (2013). Documento Orientador para a Implementação da Vigilância em Saúde de Populações Expostas a Agrotóxicos. Recuperado em 11 de março de 2020, de https://bvsms.saude.gov.br/bvs/publicacoes/relatorio_nacional_vigilancia_populacoes_ expostas_agrotoxicos.pdf 
Brasil. Ministério da Saúde. Secretaria de Vigilância em Saúde. (2018). Relatório Nacional de Vigilância em Saúde de Populações Expostas a Agrotóxicos. Recuperado em 20 de setembro de 2018, de http://bvsms.saude.gov.br/bvs/publicacoes/relatorio_nacional_vigilancia_ populacoes_expostas_agrotoxicos.pdf.

Brasil. Ministério do Trabalho. (1978). Norma Regulamentadora No. 15 (NR-15). Atividades e Operações Insalubres. Recuperado em 20 de setembro de 2018, de https://www.gov. br/trabalho-e-previdencia/pt-br/composicao/orgaos-especificos/secretaria-de-trabalho/ inspecao/seguranca-e-saude-no-trabalho/ctpp-nrs/norma-regulamentadora-no-15-nr-15

Carneiro, F. F., Rigotto, R. M., Augusto, L. G. S., Friedrich, K., \& Búrigo, A. C. (2015). DOSSIÊABRASCO: um alerta sobre os impactos dos agrotóxicos na saúde. Recuperado em 13 de fevereiro de 2019, de: http://www.abrasco.org.br/dossieagrotoxicos/wpcontent/uploads/2013/10/ DossieAbrasco_2015_web.pdf.

Castro, N. R., Barros, G. S. C., Almeida, A. N., Gilio, L., \& Morais, A. C. P. (2020). The Brazilian agribusiness labor market: measurement, characterization and analysis of income differentials. Revista de Economia e Sociologia Rural, 58(1), e192298. http://dx.doi.org/10.1590/18069479.2020.192298

DATASUS. (2021) Recuperado em 19 de maio de 2019, de: http://www.datasus.gov.br.

Dhananjayan, V., \& Ravichandran, B. (2018). Occupational health risk of farmers exposed to pesticides in agricultural activities. Current Opinion In Environmental Science \& Health, 4, 31-37. http://dx.doi.org/10.1016/j.coesh.2018.07.005

Embrapa. (2021). Consulte o módulo fiscal de seu município. Recuperado em 20 de fevereiro de 2020, de https://www.embrapa.br/codigo-florestal/area-de-reserva-legal-arl.

Embrapa. (2004). Manual de segurança e qualidade para a cultura da maçã. Recuperado em 20 de fevereiro de 2020, de https://ainfo.cnptia.embrapa.br/digital/bitstream/item/18220/1/ MANUALSEGURANCAQUALIDADEParaaculturadamaca.pdf.

Faria, N. M. X, Rosa, J. A. R., \& Facchini, L. A. (2009). Intoxicações por agrotóxicos entre trabalhadores rurais de fruticultura, Bento Gonçalves (RS). Revista de Saúde Pública, 43(2), 335-344. https://doi.org/10.1590/S0034-89102009005000014.

Faria, N. M. X., Facchini, L. A., \& Fassa, A. G., Tomasi, E. (2000). Processo de produção rural e saúde na serra gaúcha: um estudo descritivo. Cadernos de Saúde Pública, 16(1), 115-128. https://doi.org/10.1590/S0102-311X2000000100012.

Faria, N. M. X., Fassa, A. G., \& Facchini, L. A. (2007). Intoxicação por agrotóxicos no Brasil: os sistemas oficiais de informação e desafios para realização de estudos epidemiológicos. Revista Ciência \& Saúde Coletiva, 12(1), 25-38. https://doi.org/10.1590/S1413-81232007000100008.

Faria, N. M., Fass, A. G., Meucci, R. D., \& Fiori, N. S. (2014). Occupational exposure to pesticides, nicotine and minor psychiatric disorders among tobacco farmers in southern Brazil. NeuroToxicology, 45, 347-354. Recuperado em 09 de abril de 2020, de https://www. sciencedirect.com/science/article/pii/S0161813X14000837

Fioravanço, J. C., \& Santos, R. S. S. (2013). Maçã - o produtor pergunta, a Embrapa responde. Recuperado em 20 de fevereiro de 2020, de https://www.infoteca.cnptia.embrapa.br/ infoteca/bitstream/doc/964485/1/500perguntasmaca.pdf.

Instituto Nacional de Colonização e Reforma Agrária - INCRA. (2021). Recuperado em 12 de fevereiro de 2019, de https://www.gov.br/incra/pt-br 
Instituto Brasileiro de Geografia e Estatística - IBGE. (2017). Censo Agropecuário, 2017, resultados preliminares. Recuperado em 12 de fevereiro de 2019, de https://biblioteca.ibge.gov.br/ visualizacao/periodicos/3093/agro_2017_resultados_preliminares.pdf.

Instituto Brasileiro de Geografia e Estatística - IBGE. (2021). IBGE Cidades - Vacaria (RS). Recuperado em 02 de fevereiro de 2020, de https://cidades.ibge.gov.br/brasil/rs/vacaria/panorama.

Jardim, I. C. S. F., Andrade, J. A., \& Queiroz, S. C. N. (2009). Resíduos de agrotóxicos em alimentos: uma preocupação ambiental global - um enfoque às maçãs. Química Nova, 32(4), 996-1012. Recuperado em 20 de março de 2020, de https://www.scielo.br/j/qn/a/j5MZFXpYTWKhQ 3GjjgKpW6h/?lang=pt

Kim, K., Kabir, E. \& Jahan, S. A. (2017). Exposure to pesticides and the associated human health effects. Science Of The Total Environment, 575, 525-535. http://dx.doi.org/10.1016/j.scitotenv

Londres, F. (2011). Agrotóxicos no Brasil: um guia para ação em defesa da vida. Recuperado em 10 de setembro de 2020, de https://br.boell.org/sites/default/files/agrotoxicos-nobrasil-mobile.pdf.

Lopes, C. V. A. \& Albuquerque, G. S. C. (2018). Agrotóxicos e seus impactos na saúde humana e ambiental: uma revisão sistemática. Saúde em Debate, 42(117), 518-534. https://doi. org/10.1590/0103-1104201811714.

Paraná. Secretaria de Estado da Saúde do Paraná. (2013). Protocolo de avaliação das intoxicações crônicas por agrotóxicos. Recuperado em 20 de setembro de 2018, de http://renastonline. ensp.fiocruz.br/recursos/protocolo-avaliacao-intoxicacoes-cronicas-agrotoxicos.

Pereira, G. E., Rauber, L. R., Sequinatto, L., \& Guazelli, F. V. (2021). Propriedades físicas de solos sob diferentes sistemas de cultivo de soja em Vacaria, Rio Grande do Sul. Brazilian Journal of Development, 7(6):55838-50. Recuperado em 21 de julho de 2021, de: https://www. brazilianjournals.com/index.php/BRJD/article/view/30920.

Preza, D. L. C. \& Augusto, L. G. S. (2012). Vulnerabilidades de trabalhadores rurais frente ao uso de agrotóxicos na produção de hortaliças em região do Nordeste do Brasil. Revista Brasileira de Saúde Ocupacional, 37(125), 89-98. http://dx.doi.org/10.1590/S0303-76572012000100012.

Rocha Júnior, A. B., Freitas, J. A., Cassuce, F. C. C. \& Costa, S. M. A. L. (2019). Análise dos determinantes da utilização de assistência técnica por agricultores familiares do Brasil em 2014. Revista de Economia e Sociologia Rural, 57(2), 181-197. https://doi.org/10.1590/18069479.2019.184459.

Rocha, L. P., Cezar-Vaz, M. R., Almeida, M. C., Borges, A. M., Silva, M. S., \& Sena-Castanheira, J. (2015). Workloads and occupational accidents in a rural environment. Texto \& Contexto Enfermagem, 24(2), 325-335. https://doi.org/10.1590/0104-07072015000480014.

Sabarwal, A., Kumar, K. \& Singh, R. P. (2018). Hazardous effects of chemical pesticides on human health-Cancer and other associated disorders. Environmental Toxicology And Pharmacology, 63, 103-114. http://dx.doi.org/10.1016/j.etap.2018.08.018.

Sampaio, R. M., \& Fredo, C. E. (2021). Características socioeconômicas e tecnologias na agricultura: um estudo da produção paulista de amendoim a partir do Levantamento das Unidades de Produção Agropecuária (LUPA) 2016/17. Revista de Economia e Sociologia Rural, 59(4), e236538. http://dx.doi.org/10.1590/1806-9479.2021.236538.

Santos, G., \& Vieira Filho, J. E. (2012). Heterogeneidade produtiva na agricultura brasileira: elementos estruturais e dinâmicos da trajetória produtiva recente. Brasília, DF: Ipea. Recuperado em 26 de novembro de 2021, de http://repositorio.ipea.gov.br/handle/11058/1138. 
Santos, A. C. M., Soares, I. P., Moreira, J. C., Farias, M. B. M., Dias, R. B. F., \& Farias, K. F. (2017). Profile of clinical information in medical records of tobacco farmers in Alagoas, Brazil. Revista Brasileira de Medicina do Trabalho, 15(4), 310-316. http://dx.doi.org/10.5327/ z1679443520170045.

Silva, T. P. P., Moreira, J. C., \& Peres, F. (2012). Serão os carrapaticidas agrotóxicos? Implicações na saúde e na percepção de riscos de trabalhadores da pecuária leiteira. Revista Ciência \& Saúde Coletiva, 17(2), 311-325. https://doi.org/10.1590/S1413-81232012000200006.

Soares, W. L. \& Porto, M. F. (2007). Atividade agrícola e externalidade ambiental: uma análise a partir do uso de agrotóxicos no cerrado brasileiro. Revista Ciência \& Saúde Coletiva, 12(1), 131-143. http://dx.doi.org/10.1590/S1413-81232007000100016 .

Souza, P. M., Fornazier, A., Souza, H. M., \& Ponciano, N. J. (2019). Diferenças regionais de tecnologia na agricultura familiar no Brasil. Revista de Economia e Sociologia Rural, 57(4), http://dx.doi.org/10.1590/1806-9479.2019.169354

Spadotto, C.A., Gomes, M. A. F., Luchini, L. C., Andréa, M. M. (2004). Monitoramento do Risco Ambiental de Agrotóxicos: princípios e recomendações. Recuperado em 20 de fevereiro de 2020, de https://www.embrapa.br/busca-de-publicacoes/-/publicacao/14523/monitoramentodo-risco-ambiental-de-agrotoxicos-principios-e-recomendacoes 